\title{
FORMAÇÃO DOCENTE EM EAD: A EXPERIÊNCIA DE ENSINO, PESQUISA E EXTENSÃO NO CURSO DE LICENCIATURA EM COMPUTAÇÃO
}

\author{
FORMACIÓN DOCENTE EN EAD: LA EXPERIENCIA DE ENSEÑANZA, \\ INVESTIGACIÓN Y EXTENSIÓN EN EL CURSO DE LICENCIATURA EN \\ COMPUTACIÓN
}

\author{
EDUCATIONAL TRAINING IN EAD: THE EXPERIENCE OF \\ TEACHING, RESEARCH AND EXTENSION IN THE COURSE OF \\ GRADUATION COMPUTING
}

\author{
Noeli Antônia Pimentel VAZ ${ }^{1}$ \\ Gislene Lisboa de OLIVEIRA ${ }^{2}$ \\ Pollyana dos Reis Pereira FANSTONE ${ }^{3}$
}

RESUMO: A Universidade tem como um de seus pilares a tríade ensino, pesquisa e extensão. Somente por meio da articulação entre essas três atividades, as instituições de ensino superior conseguem cumprir com seu papel: formar integralmente cidadãos capazes de atuar crítica e reflexivamente na sociedade. Este trabalho tem por objetivo apresentar a experiência do Curso de Licenciatura em Computação do Centro de Ensino e Aprendizagem em Rede da Universidade Estadual de Goiás no componente curricular Estágio Supervisionado. Por meio desse componente os alunos foram para escolas de Ensino Fundamental em seus municípios para analisar e intervir no sentido de propor melhorias no processo ensino-aprendizagem, utilizando recursos computacionais com funcionalidades pedagógicas. Após o percurso de investigação e intervenção, os acadêmicos apresentaram seus trabalhos de pesquisa a uma comissão composta por docentes da área no I Encontro Científico das Licenciaturas do CEAR/UEG e, destes trabalhos, os melhores foram selecionados e apresentaram seus trabalhos, também, no III Congresso de Ensino, Pesquisa e Extensão da UEG. Nestes dois momentos os acadêmicos tiveram acesso a informações atualizadas na sua área de formação profissional e/ou de estudo; discutiram com a comunidade acadêmica, por meio da apresentação de banners, temáticas relevantes. Dessa forma, tiveram a oportunidade de refletir o panorama de formação profissional das licenciaturas, trocando experiências e interagindo com professores/pesquisadores da área.

PALAVRAS-CHAVE: Formação de professores. Ensino. Pesquisa. Extensão. EaD.

\footnotetext{
${ }^{1}$ Universidade Estadual de Goiás (Ueg) - Anápolis - GO - Brasil. Centro de Ensino e Aprendizagem em Rede. Mestre em Engenharia de Produção e Sistemas pela Pontifícia Universidade Católica de Goiás. Email: noeli@ueg.br.

${ }^{2}$ Universidade Estadual de Goiás (Ueg) - Anápolis - GO - Brasil. Doutoranda em Educação pela Pontifícia Universidade Católica de Goiás. E-mail: gislene.lisboa@ueg.br.

${ }^{3}$ Universidade Estadual de Goiás (Ueg) - Anápolis - GO - Brasil. Mestre em Educação pela Pontifícia Universidade Católica de Goiás. E-mail: pollyana_reis@ homail.com.
} 
RESUMEN: La Universidad tiene como uno de sus pilares la tríada enseñanza, investigación y extensión. Sólo por medio de la articulación entre esas tres actividades, las instituciones de enseñanza superior logran cumplir con su papel: formar integralmente a ciudadanos capaces de actuar crítica y reflexivamente en la sociedad. Este trabajo tiene por objetivo presentar la experiencia del Curso de Licenciatura en Computación del Centro de Enseñanza y Aprendizaje en Red de la Universidad Estatal de Goiás en el componente curricular Etapa Supervisada. Por medio de este componente los alumnos se dirigieron a las escuelas de Enseñanza Fundamental en sus municipios para analizar e intervenir con la intención de proponer mejorías en el proceso enseñanza-aprendizaje, utilizando recursos computacionales con funcionalidades pedagógicas. Después del recorrido de investigación e intervención, los académicos presentaron sus trabajos de investigación a una comisión compuesta por docentes del área en el I Encuentro Científico de las Licenciaturas del CEAR / UEG, donde fueron seleccionados los mejores y luego presentados en el III Congreso de Enseñanza, Investigación y Extensión de la UEG. En estos dos momentos los académicos tuvieron acceso a informaciones actualizadas en su área de formación profesional y / o de estudio; discutieron con la comunidad académica, por medio de la presentación de afiches, temáticas importantes. De esta forma, tuvieron la oportunidad de reflejar el panorama de formación profesional de las licenciaturas, intercambiando experiencias e interactuando con profesores / investigadores del área.

PALABRAS-CLAVE: Formación de profesores. Enseñanza. Búsqueda. Extensión. $E a D$.

ABSTRACT: The University has as one of its pillars the teaching, research and extension triad. Only through the articulation between these three activities can higher education institutions fulfill their role: to fully form citizens capable of acting critically and reflexively in society. This work aims to present the experience of the Degree in Computer Science of the Center for Teaching and Learning in Network of the State University of Goiás in the curricular component Supervised Stage. Through this component the students went to elementary schools in their municipalities to analyze and intervene to propose improvements in the teaching-learning process, using computational resources with pedagogical functionalities. After the course of research and intervention, the academics presented their research papers to a committee made up of professors from the area at the First Scientific Meeting of the CEAR / UEG, and from these works, the best ones were selected and presented their work, also in the III Congress of Teaching, Research and Extension of UEG. In these two moments the academics had access to updated information in their area of professional training and / or study; Discussed with the academic community, through the presentation of relevant thematic banners. In this way, they had the opportunity to reflect the professional training panorama of the degrees, exchanging experiences and interacting with teachers / researchers in the area.

KEYWORDS: Teacher training. Teaching. Search. Extension. EaD.

\section{Introdução}

RPGE- Revista on line de Política e Gestão Educacional, Araraquara, v.21, n.esp.3, p. 1611-1625, dez., 2017. 
A sociedade vive, na contemporaneidade, um processo de mudanças contínuas. As tecnologias digitais foram inseridas ao desenvolvimento do processo educativo. Neste contexto, a Educação a Distância $(\mathrm{EaD})$ ocupa uma posição estratégica para satisfazer as amplas e diversificadas necessidades de qualificação e formação profissional, combinando tecnologias convencionais e modernas que possibilitam o ensino individual ou em grupo, por meio de métodos de orientação e tutoria (OLIVEIRA, 2008).

A EaD ganha cada vez mais espaço e é considerada um "importante veículo para a difusão de uma nova sociabilidade, um novo modo de ser, pensar e agir" (OLIVEIRA, 2001, p. 2). As Tecnologias da Informação e Comunicação (TICs) são uma realidade a ser pensada e utilizada pelas escolas no sentido de contribuir e enriquecer o processo ensino-aprendizagem.

A mesma autora relata ainda que a educação se utiliza do avanço das tecnologias, com diferentes modos de fazer a educação formal, para alcançar seus objetivos que são ensinar, educar, contribuir na formação e, sobretudo, qualificar o homem para o trabalho e para conviver socialmente.

Diante dessa realidade, o curso de Licenciatura em Computação na modalidade a distância vem de encontro com a demanda por profissionais aptos a utilizar as TICs no contexto educativo, por meio da introdução do pensamento algorítmico na educação básica e sua aplicação na resolução de problemas transversais a todas as áreas do conhecimento. O Licenciado em Computação atua no sentido de propor, planejar e desenvolver recursos computacionais com funcionalidades pedagógicas, dinamizando o uso das TICs em contextos escolares e não escolares.

Neste trabalho pretende-se fazer um relato de experiência vivenciada durante a realização do componente curricular Estágio Supervisionado II neste curso, o qual tem como principal objetivo: estimular os acadêmicos para uma atitude investigativa em relação a temas relevantes, diretamente relacionados à utilização de recursos tecnológicos no processo educativo.

\section{Formação de professores em educação a distância}

A formação de professores é uma temática amplamente discutida nos ambientes acadêmicos, visto que este processo formativo é um fator essencial para todo o contexto de ensino e aprendizagem. Certamente que toda a sociedade ganhará, se tivermos em 
nosso país professores qualificados, competentes, compromissados e valorizados aptos a formarem cidadãos críticos e reflexivos. Para isso, é fundamental que os cursos de graduação e pós-graduação ofereçam, além de conhecimentos científicos, atividades práticas que articulem a teoria e a prática (PIMENTA; LIMA, 2004).

Freitas (1992 p. 8), destaca que o profissional da educação "é aquele que foi preparado para desempenhar determinadas relações no interior da escola ou fora dela, onde o trato com o trabalho pedagógico ocupa posição de destaque, constituindo mesmo o núcleo central de sua formação". Sendo assim, para o autor, não há uma consubstanciação de "trabalho pedagógico com docência, [...] sendo então a docência um dos aspectos da atuação do profissional da educação" (p. 9). No entanto, ainda de acordo com Freitas, há que se reafirmar que a formação do profissional da educação é a sua formação como educador, com ênfase na atuação como professor.

Para tal, faz-se necessário a integração entre o ensino, a pesquisa e a extensão. O estágio é um momento importante nos cursos de formação de professores, pois é ali que o acadêmico poderá refletir, discutir e intervir conforme seu aprendizado teórico no curso. É esse "agir docente", como oportunidade no componente curricular de Estágio Supervisionado, que proporcionará a construção de novos conhecimentos tanto para o acadêmico como para a sociedade.

Nesse sentido, Oliveira e Cunha (2014) relatam que o Estágio Supervisionado seja um dos principais componentes curriculares, pois os que aprendem e os que ensinam são sujeitos envolvidos em um processo de formação pela ação, de construção e de criação, de modo a alterar o modo de pensar do acadêmico estagiário sobre a construção de sua práxis pedagógica.

O princípio dessa integração entre os pilares em questão reflete um conceito de qualidade do desempenho acadêmico capaz de favorecer a autorreflexão crítica, a emancipação teórico-prática e o significado de responsabilidade social proporcionado pela aproximação entre a universidade e a comunidade" (PIVETTA et al, 2014, p. 378).

Pensando a partir de uma concepção sobre a formação docente voltada para a construção de uma cidadania consciente e ativa, que ofereça aos alunos bases sólidas que os permitam posicionar-se frente às contínuas transformações sociais, incorporando-as na vida produtiva e sociopolítica (BORSSOI, 2008, p. 14), é que, neste trabalho, propomos pensar na formação docente pautada no ensino, pesquisa e extensão. Para a referida autora "não basta ao professor adquirir conhecimentos sobre 
seu trabalho, é fundamental que ele saiba disponibilizá-los, transformando-os em ação"

\section{Práxis Pedagógica}

O processo educacional tem como objetivo principal a elucidação da historicidade do homem. Ao nascer, o homem se envolve em uma rede de relações interativas e uma estrutura de significados. Por meio do processo educativo, o homem vivencia essa rede de relações e desenvolve a compreensão da estrutura de significados (ORTIZ, 2003). Quando ele adquire a capacidade potencial de transformar a rede dessas relações interativas e mudar a estrutura de significados é porque atingiu a plena e completa consciência de sua historicidade. Com essa condição, o homem identifica-se e identifica o outro criticamente.

Kraut (2009) define a práxis como ação no sentido intenso do termo e afirma estar essa relacionada diretamente com a capacidade de discernimento necessária para se agir corretamente. Em outras palavras, constitui-se como o próprio objetivo da ação.

Para Lima e Gonçalves, (2009) a práxis se refere ao atuar responsável, independente e guiado pelas ideias do homem. Quando se dá a instrumentalização de um objeto ou poiésis isso aponta para um resultado concreto, e numa obra, o objeto realizado só recebe seu valor e sentido ao final. De forma contrária, o atuar práxico sempre leva um sentido e um valor em si mesmo e já cumpre seu objetivo pelo mero fato de se suceder como algo correto e justo, independentemente se o agente atinge na realidade o que desejava mediante sua ação.

O professor deve ser um profissional com competências: científica, pedagógica e didática. Ele deve estar preparado para refletir sua prática pedagógica, adaptando- a às mudanças exigidas pelo contexto em que se encontra inserido e apto a enfrentar novas realidades.

A formação docente deve ser concebida a partir deste pressuposto é compreendida "como um trabalho de reflexividade crítica sobre as práticas e de (re)construção permanente de uma identidade pessoal e profissional, em interação mútua" (CANDAU, 1996, p. 150). A constituição de práticas que sejam dinâmicas e que contribuam com a sociedade perpassa pela necessidade de mudar as práticas educativas obsoletas, até então utilizadas por professores e que a partir da problematização das questões postas pela prática docente, se tornam evidentes para os que nela atuam. E, nesse sentido a práxis pedagógica é a ação evidenciada pela transformação, sendo a articulação entre as questões da prática docente e as teorias da educação de modo que o ensino, a pesquisa e a extensão possam ser os pilares na 
formação docente.

\title{
Ensino, Pesquisa e Extensão
}

As Instituições de Ensino Superior têm como uma de suas principais funções na sociedade a democratização do conhecimento científico. É possível afirmar que isso somente é viável por meio da relação ensino x pesquisa x extensão. Na pesquisa iniciase o diálogo entre a produção científica e o mundo, o objeto que se deseja conhecer é construído. Somente por meio dela é possível gerar o conhecimento. No ensino ocorre, efetivamente, a transformação do conhecimento em conteúdo de ensino, bem como a sua disseminação e repasse. Já na extensão a instituição retorna à sociedade os "investimentos" concedidos a ela, mediante o desenvolvimento de projetos que a favoreçam, bem como a formação integral do acadêmico.

De acordo com Severino (2007, p. 23),

\begin{abstract}
A Universidade, em seu sentido mais profundo, deve ser entendida como uma entidade que, funcionária do conhecimento, destina-se a prestar serviço à sociedade [...] Para dar conta desse compromisso, desenvolve atividades específicas - ensino, pesquisa e extensão. Atividades essas que devem ser efetivamente articuladas entre si, cada uma assumindo uma perspectiva de prioridade nas diversas circunstâncias histórico-sociais em que os desafios humanos são postos.
\end{abstract}

O autor ainda afirma que ensino e aprendizagem só serão motivadores se seu processo se der como processo de pesquisa "Praticar a pesquisa é vivenciar a forma mais privilegiada de aprender" (p. 26).

É a partir dessa realidade que a indissociabilidade entre ensino, pesquisa e extensão tornou-se requisito obrigatório à prática da Universidade desde 1988 com a sua inclusão no artigo 207 da Constituição da República Federativa do Brasil.

Para que as Instituições de Ensino Superior cumpram seu papel na sociedade, a tríade ensino, pesquisa e extensão deve estar intimamente integrada e articulada. Embora estas atividades se apresentem de forma distintas, elas devem interagir no sentido de possibilitar vivências que estimulem o questionamento sobre a realidade. Somente por meio dessa indissociabilidade a realidade observada na sociedade se transforma em conhecimento.

Para se legitimar como uma Instituição de Ensino Superior é fundamental que os interesses da Universidade estejam voltados para os interesses/objetivos da população como um todo. Caso contrário é o simples repasse de informações, "o saber

RPGE- Revista on line de Política e Gestão Educacional, Araraquara, v.21, n.esp.3, p. 1611-1625, dez., 2017. 
a serviço apenas do fazer" (SEVERINO, 2007, p. 32).

Pensando a partir de uma concepção sobre a formação docente voltada para a construção de uma cidadania consciente e ativa, que ofereça aos alunos bases sólidas que os permitam posicionar-se frente às contínuas transformações sociais, incorporando-as na vida produtiva e sociopolítica (Borssoi, 2008), é compreendemos a formação docente pautada no ensino, pesquisa e extensão, corroborando com o pensamento da referida autora que diz "não basta ao professor adquirir conhecimentos sobre seu trabalho, é fundamental que saiba disponibilizá-los, transformando-os em ação" (p. 14).

\section{Licenciatura em Computação CEAR/UEG}

Os cursos superiores de Bacharelado e Licenciatura em computação compreendem o papel relevante dos computadores na sociedade. Atualmente, estes, são elementos primordiais, nas comunicações, na saúde, na gestão, nas artes e na pesquisa. É possível afirmar, sem exagero, que a vida das pessoas depende de sistemas de computação e de profissionais que os mantém.

O curso de Licenciatura em Computação é ofertado na Universidade Estadual de Goiás desde 2009 na modalidade a distância, em parceria com a Universidade Aberta do Brasil - UAB. Atualmente, encontra-se um sua segunda oferta para os seguintes polos UAB, conforme apresenta a Tabela 1 .

Tabela 1: Polos UAB - Licenciatura em Computação

\begin{tabular}{ll}
\hline Polo UAB \\
\hline Alto Paraíso \\
Alexânia \\
Aparecida de Goiânia \\
Jussara \\
Mineiros \\
São Simão \\
Uruana \\
\hline
\end{tabular}

Fonte: autores

É objetivo do curso, contribuir para a formação de profissionais na área de Computação para essas regiões do estado de Goiás. Estes acadêmicos, ao final do 
curso, serão capazes de atuar em ambientes escolares e/ou não escolares nas diversas áreas que envolvam as Tecnologias da Informação e Comunicação aplicadas à Educação. Pressupostos ético-epistemológicos, tendo como referência, os princípios da autonomia e da flexibilidade, pautado nas Diretrizes Curriculares Nacionais (DCNs) são as bases do curso.

A inserção de temáticas contemporâneas, pautadas na abordagem interdisciplinar, organizadas em núcleos, com disciplinas ofertadas semestralmente são previstos na estrutura curricular do curso. Os materiais didáticos são desenvolvidos por professores pesquisadores e as disciplinas planejadas pelos professores formadores.

O estudante tem como apoio um sistema de tutoria estruturado no Ambiente Virtual de Ensino Aprendizagem - Moodle e em Polos de Atendimento Presencial. O acompanhamento da disciplina é realizado pelos tutores a distância e presenciais nos respectivos polos.

A proposta metodológica adotada no curso considera, em síntese, diretrizes que devem oportunizar a formação que privilegie competências profissionais, sociais e políticas, baseadas nos aspectos, científico-didático, condizente com as exigências da ciência histórica, expressos por meio de duas dimensões: Epistemológica, que diz respeito aos conteúdos teórico-metodológico-didáticos ligados ao currículo da Licenciatura em Computação e Profissionalizante, que contemplando a primeira, diz respeito aos suportes teórico-práticos que possibilitam uma compreensão do fazer histórico e a construção de competências para atuação em todas as suas relações sociopolíticas e culturais nas perspectivas da docência e da pesquisa.

A estrutura do curso de Licenciatura em Computação aqui apresentado tem por base os princípios que contemplam as exigências da formação do professor/profissional de Computação, levando em consideração a identificação de necessidades atuais e prospectivas da sociedade, assim como da legislação vigente.

A perspectiva metodológica do curso está embasada na concepção de que a aprendizagem é um processo que se constrói na interação professor, aluno e conhecimento. Os conteúdos pertinentes a cada disciplina são trabalhados em suas especificidades e em interdisciplinaridade com outras disciplinas.

O curso assume a pesquisa como princípio educativo e princípio cognitivo com vistas à promoção da investigação, interação entre teoria e prática na construção de uma práxis, produção de conhecimentos com vistas à formação de profissionais autônomos e capazes de estabelecer relações entre as diversas áreas do conhecimento.

RPGE- Revista on line de Política e Gestão Educacional, Araraquara, v.21, n.esp.3, p. 1611-1625, dez., 2017. 


\section{Estágio Supervisionado}

O Estágio Supervisionado constitui-se em componente curricular do currículo pleno dos cursos de licenciatura nas suas respectivas áreas de conhecimento, totalizando 400 horas, subdivididos em 200 horas para o Estágio Supervisionado em Computação - Ensino Fundamental e 200 horas para o Estágio Supervisionado em Computação - Ensino Médio. É obrigatório que este trabalho seja desenvolvido em Instituições de Ensino de Educação Básica ou instituições não formais de ensino a partir do início da segunda metade do curso.

De acordo com o Art. 2. ${ }^{\circ}$ do Regulamento das Diretrizes Básicas para o Estágio Supervisionado dos Cursos de Graduação da UEG, “o estágio supervisionado submetese às determinações contidas na Legislação Federal, Lei N. 11.788/2008, às Diretrizes Curriculares Nacionais dos Cursos, ao Regimento Geral da UEG e às regulamentações específicas.

[...] o Estágio não pode ser encarado como uma tarefa burocrática a ser cumprida formalmente...Deve, sim, assumir a sua função prática, revisada numa dimensão mais dinâmica, profissional, produtora, de troca de serviços e de possibilidades de abertura para mudanças (KULCSAR, 1994, p. 65).

Incorporado no curso como um elemento formador de cidadania, o Estágio Curricular Supervisionado, deve se alinhar às dimensões teórica e prática, numa perspectiva reflexiva, crítica e investigativa da formação profissional do acadêmico, pois além de fortalecer a articulação entre a teoria e a prática, tem um papel social relevante. O estágio é a prática profissionalizante direta e específica, devendo ser devidamente supervisionada, orientada e qualificada para a formação de profissionais para cumprirem com os objetivos da profissão.

O Estágio Curricular Supervisionado dos cursos de licenciatura caracteriza-se por apresentar um conjunto de atividades voltadas para a formação profissional, por meio da vivência de situações reais do processo de ensino e de aprendizagem. Esta experiência propicia ao aluno estagiário, ao longo da realização do estágio a vivência no exercício da profissão, possibilitando a sua participação na dinâmica das escolas e/ou instituições. Todo esse trabalho é orientado por professores formadores e professores tutores, como consta no Regulamento do Estágio Supervisionado do CEAR e demais orientações da Pró-Reitoria de Graduação da UEG.

RPGE- Revista on line de Política e Gestão Educacional, Araraquara, v.21, n.esp.3, p. 1611-1625, dez., 2017. 
Portanto, o Estágio Curricular Supervisionado em um conceito mais restrito consta de atividades práticas pré-profissionais, exercidas em situações reais de trabalho, em um processo interdisciplinar avaliativo e criativo destinado a articular teoria e prática.

Segundo artigo $1^{\circ}$ das Diretrizes Básicas para o Estágio Supervisionado dos Cursos de Graduação da Universidade Estadual de Goiás:

Estágio é ato educativo escolar supervisionado, desenvolvido no ambiente de trabalho de trabalho articulado às outras atividades realizadas na UEG.

$\mathrm{Na}$ proposta prevista no Projeto Pedagógico do Curso de Licenciatura em Computação, o acadêmico após visitar e analisar o ambiente escolar ou não escolar em que irá atuar deve propor melhorias ao processo ensino aprendizagem por meio da utilização de recursos computacionais como por exemplo: softwares educativos, objetos de aprendizagem, capacitação de professores para o uso das TICs e outros.

O artigo $8^{\circ}$ apresenta como objetivos do Estágio Curricular Supervisionado: I. permitir o desenvolvimento de habilidades técnico-científicas, visando uma melhor qualificação do futuro profissional por meio da aprendizagem de conhecimentos e de saberes, tendo em vista uma formação complexa, diversificada, crítica e propositiva em relação ao mundo do trabalho; II. realizar atividades de investigação, pesquisa, análise e intervenção na realidade profissional específica da área de formação, promovendo a integração da Universidade com a sociedade; III. subsidiar o colegiado de curso, com dados, análises e conhecimentos que visem a melhoria da formação profissional; IV. promover a aproximação e diálogo da Universidade com os campos de estágio e a sociedade; V. identificar e fortalecer os campos de estágio como espaço formativo; VI. articular teoria e prática no processo de formação humana e profissional.

O Estágio Supervisionado I, ofertado em 2015/2 é uma etapa de observação e desenvolvimento do Projeto de Intervenção. No Estágio Supervisionado II, ofertado em 2016/1, o acadêmico realizou a aplicação do Projeto de Intervenção proposto. A Tabela 2 apresenta o quantitativo, por Polo, de alunos matriculados no Estágio Supervisionado II.

Tabela 2: Matrículas - Estágio Supervisionado II em 2016/1

\begin{tabular}{cc}
\hline Polo UAB & Matrículas \\
\hline Alto Paraíso & 25 \\
Alexânia & 29
\end{tabular}

RPGE- Revista on line de Política e Gestão Educacional, Araraquara, v.21, n.esp.3, p. 1611-1625, dez., 2017. 


$\begin{array}{cc}\text { Aparecida de Goiânia } & 15 \\ \text { Jussara } & 22 \\ \text { Mineiros } & 5 \\ \text { São Simão } & 7 \\ \text { Uruana } & 17\end{array}$

Fonte: Elaborado pelos autores

\section{O I Encontro Científico da Licenciaturas do CEAR/UEG e o III Congresso de Ensino, Pesquisa e Extensão da UEG}

O I Encontro Científico das Licenciaturas do CEAR/UEG foi um evento organizado pelos cursos de graduação do CEAR no intuito de envolver seus acadêmicos em práticas de construção de conhecimento, mediante projetos de intervenção do componente curricular Estágio Supervisionado. Foi um momento relevante e enriquecedor, pois os alunos puderam aplicar seus conhecimentos teóricopráticos adquiridos a partir da tomada de consciência da realidade educacional das escolas da rede estadual de ensino do Estado de Goiás.

O evento realizou-se nos Polos UAB nos dias 10 e 11; 18 e 19 de junho de 2016, quando os acadêmicos apresentaram, em formato de banner, seus trabalhos de pesquisa desenvolvidos na Etapa II do componente curricular Estágio Supervisionado. Os trabalhos foram avaliados por uma comissão científica composta por docentes da área. Durante o percurso de confecção do banner, bem como do projeto de intervenção, os alunos tiveram a orientação e apoio dos professores da disciplina, bem como dos tutores, mostrando-se motivados e participativos.

No Encontro Científico os alunos tiveram acesso a informações atualizadas na sua área de formação profissional e/ou de estudo; discutiram com a comunidade acadêmica, por meio de seus banners, temáticas relevantes. Dessa forma, os acadêmicos tiveram a oportunidade de refletir o panorama de formação profissional das licenciaturas, trocando experiências e interagindo com professores e pesquisadores da área.

Ao todo, 91 (noventa e um) acadêmicos do curso de Licenciatura em Computação participaram do Encontro, apresentando temas relevantes como: Jogos educativos, Blog como instrumento pedagógico, Google Earth no ensino da Geografia, Softwares educacionais na Matemática, Leitura Virtual para disciplina de Português, dentre outros. O quantitativo de trabalhos apresentados no evento está exibidos na

RPGE- Revista on line de Política e Gestão Educacional, Araraquara, v.21, n.esp.3, p. 1611-1625, dez., 2017. 
Tabela 3.

Tabela 3: Trabalhos Apresentados no I Encontro Científico das Licenciaturas

\begin{tabular}{cc}
\hline Polo UAB & Matrículas \\
\hline Alto Paraíso & 22 \\
Alexânia & 15 \\
Aparecida de Goiânia & 9 \\
Jussara & 22 \\
Mineiros & 3 \\
São Simão & 6 \\
Uruana & 14
\end{tabular}

Fonte: Elaborado pelos autores

Os melhores trabalhos apresentados no Encontro foram selecionados para participarem do III Congresso de Ensino, Pesquisa e Extensão da UEG - CEPE. O CEPE é um evento aberto aos acadêmicos: bolsistas, voluntários da Iniciação Científica e Tecnológica, matriculados nos cursos de Lato Sensu da UEG, mestrandos e doutorandos dos programas de Pós-graduação Stricto Sensu da instituição.

O Congresso, neste ano, teve como tema "Inovação: Inclusão Social e Direitos" e ocorreu nos dias 19, 20 e 21 de outubro no Câmpus de Pirenópolis/UEG. Os alunos além da oportunidade de divulgar seus trabalhos, puderam participar de minicursos, mesas redondas e apresentações culturais.

Os trabalhos selecionados foram os seguintes: Utilização do software educacional Duolingo como instrumento de reforço no aprendizado da língua inglesa do $7^{\circ}$ ano; S.O.S Rio Uru na Internet: blog como perspectiva de aproximação entre escola e família; Recursos tecnológicos digitais no ensino da matemática; As novas tecnologias na escola: desafios e perspectivas; Capacitação de professores em Linux Educacional e seus aplicativos; Uso das tecnologias em sala de aula e seus reflexos no processo de ensino e aprendizagem.

A terceira edição do Congresso de Ensino, Pesquisa e Extensão mostrou os bons frutos colhidos do investimento feito pela Instituição no campo acadêmico. Os mais de 1.400 trabalhos inscritos, de alunos de graduação e pós-graduação, nas várias áreas de conhecimento mostram a importância da articulação entre o ensino, a pesquisa e a extensão na formação docente; bem como a relevância estratégica da Universidade para o campo acadêmico estadual.

\section{Considerações finais}

RPGE- Revista on line de Política e Gestão Educacional, Araraquara, v.21, n.esp.3, p. 1611-1625, dez., 2017. 
Pelo estudo realizado foi possível verificar a importância do componente curricular Estágio Supervisionado na articulação entre as atividades de ensino, pesquisa e extensão nos cursos de graduação, mais especificamente para as licenciaturas. Este componente do currículo deve ser compreendido como o "espaço" que oportuniza a efetivação do conhecimento e dos saberes necessários à prática docente. Dessa forma, deve ser trabalhado de forma intencional e fundamentada, pois somente assim será possível integrar teoria e prática, exercendo a práxis pedagógica necessária na formação docente.

O professor planeja suas atividades por meio de um trabalho intelectual, pensando sobre as ciências, analisando os instrumentos de ensino e selecionando os recursos didáticos e computacionais a serem utilizados. A docência deve ser entendida como uma ação que envolve mais que a atuação em sala de aula.

Para Saviani (2005), o professor precisa ter conhecimento para distinguir entre aquilo que é essencial e acidental, principal e secundário, fundamental e acessório na hora de definir os pressupostos de seu trabalho e os caminhos que poderá seguir.

No Curso de Licenciatura em Computação do CEAR/UEG, os acadêmicos iniciam essa trajetória de construção de novos conhecimentos, por meio do ensino, da pesquisa e da extensão. A experiência relatada mostra que, para que o Estágio Supervisionado não seja apenas o cumprimento de tarefas e carga horária, é importante que se manifeste como uma rica (e ainda não suficientemente explorada) oportunidade para o exercício da indissociabilidade das atividades acadêmicas. Além disso, o Estágio Supervisionado é de extrema relevância quanto à sua função na formação do professor, pois se revela como uma etapa primordial na formação docente.

Conclui-se que o componente curricular Estágio Supervisionado perfaz uma etapa no curso de Licenciatura em Computação do CEAR/UEG, de contínua investigação científica, pois vai além de um simples cumprimento de exigências acadêmicas. Ele é uma oportunidade de crescimento pessoal e profissional. Além de ser um importante instrumento de integração entre universidade, escola e comunidade por meio da tríade ensino, pesquisa e extensão (FILHO, 2010). Por isso, o presente estudo foi desenvolvido a fim de trazer a público a importância do Estágio Supervisionado no processo de formação do profissional docente. Também relata a importância da experiência prática aliada aos conhecimentos teóricos na vida dos acadêmicos de graduação e a comunicação científica das experiências vivenciadas. 


\section{REFERÊNCIAS}

BORSSOI, B.L. O Estágio na Formação Docente: da teoria à prática, ação-reflexão. 1. ${ }^{\circ}$ Simpósio Nacional de Educação. XX Semana da Pedagogia. Unioeste, Cascavel/PR. novembro de 2008.

BRASIL. Congresso Nacional. Lei $\mathbf{n}^{\mathbf{0}}$ 11.788, de 25 de setembro de 2008.

CANDAU, V. M. F. A formação continuada de professores: tendências atuais. In: REALI, A. de M. R.; MIZUKAMI, M. da G. N. (Orgs). Formação de professores: tendências atuais. São Carlos: EDUFSCar, 1996.

FILHO, A. P. O Estágio Supervisionado e sua importância na formação docente. Revista P@rtes. 2010.

FREITAS, L. C. Em direção a uma política para a formação de professores. Em Aberto, Brasília, ano 12, nº 54, abr./jun. 1992.

KRAUT, R. [et al]. Aristóteles: a ética a Nicômaco. Trad. de Alfredo Storck. Porto Alegre: Artmed, 2009, 352p.

KULCSAR, R. O Estágio Supervisionado como Atividade Integradora. In PICONEZ, Stela C. B. A Prática de Ensino e o estágio supervisionado. 2. ed. Campinas: Papirus, 1994.

LIMA, M. S. L.; GONÇALVES, H. H. A práxis docente no desempenho das atividades do professor formador. In: IX Congresso Nacional de Educação - Educere, III Encontro Sulbrasileiro de psicopedagogia. Curitiba: PUCPR. 2009.

\section{OLIVEIRA, E.S.G; CUNHA, V. L. O estágio Supervisionado na formação} continuada docente a distância: desafios a vencer e construção de novas subjetividades. Publicación en línea. Murcia (España). Año V, Número 14, 31 de marzo de 2014.

OLIVEIRA, D.M. Formação de Professores em Nível Superior: o projeto veredas e a nova sociabilidade do capital. Trabalho publicado nos Anais da $31^{\mathrm{a}}$ Reunião Anual da Anped. Caxambu, 2008b.

OLIVEIRA, M. R. N. S. Do mito da tecnologia ao paradigma tecnológico; a mediação tecnológica nas práticas didático-pedagógicas. Revista Brasileira de Educação, Campinas: Autores Associados; Rio de Janeiro: ANPEd, n. 18, p. 101-107, set./dez. 2001.

ORTIZ, H. M. O professor reflexivo: (re)construindo o "ser" professor. Vargem Grande Paulista, III Congresso de Educação - MHN, 2003.

PIMENTA, S. G.; LIMA, M. S. L. Estágio e Docência. São Paulo: Cortez, 2004. 
PIVETTA, M. et al. Otimização do Moodle para dar suporte às Comunidades de Práticas Acessíveis a surdos e Ouvintes. XIX Conferência Internacional sobre Informática na Educação, TISE. No prelo 2014b.

SAVIANI, Dl. Pedagogia histórico crítica: primeiras aproximações. 9. ed. Campinas, SP: Autores Associados, 2005.

SEVERINO, A. J. Metodologia do trabalho científico. 23. ed. rev e atual. São Paulo: Cortez, 2007.

\section{Como referenciar este artigo}

VAZ, Noeli Antônia Pimentel.; OLIVEIRA, Gislene Lisboa.; FANSTONE, Pollyana dos Reis Pereira. Formação docente em EAD: A experiência de ensino, pesquisa e extensão no curso de Licenciatura em Computação. Revista on line de Política e Gestão Educacional, Araraquara, v.21, n.esp.3, p. 1611-1625, dez., 2017. ISSN: 1519-9029.

Submetido em: 14/07/2017

Aprovado em: 10/09/2017 